\title{
In Vitro and In Vivo Application of Radiolabeled Gastrin- Releasing Peptide Receptor Ligands in Breast Cancer
}

\author{
Simone U. Dalm ${ }^{1}$, John W.M. Martens ${ }^{2}$, Anieta M. Sieuwerts ${ }^{2}$, Carolien H.M. van Deurzen ${ }^{3}$, Stuart J. Koelewijn ${ }^{1}$, Erik de \\ Blois ${ }^{1}$, Theodosia Maina ${ }^{4}$, Berthold A. Nock ${ }^{4}$, Luc Brunel ${ }^{5}$, Jean-Alain Fehrentz ${ }^{5}$, Jean Martinez ${ }^{5}$, Marion de Jong ${ }^{1}$, \\ and Marleen Melis ${ }^{1}$
}

${ }^{I}$ Departments of Nuclear Medicine and Radiology, Erasmus MC, Rotterdam, The Netherlands; ${ }^{2}$ Department of Medical Oncology and Cancer Genomics Netherlands, Erasmus MC, Rotterdam, The Netherlands; ${ }^{3}$ Department of Pathology, Erasmus MC, Rotterdam, The Netherlands; ${ }^{4}$ Molecular Radiopharmacy, INRASTES, NCSR "Demokritos", Athens, Greece; and ${ }^{5}$ Institut des Biomolécules Max Mousseron, UMR5247, CNRS-UM1-UM2, Montpellier, France

Breast cancer $(\mathrm{BC})$ consists of multiple subtypes defined by various molecular characteristics, for instance, estrogen receptor (ER) expression. Methods for visualizing BC include mammography, MR imaging, ultrasound, and nuclear medicine-based methods such as ${ }^{99 \mathrm{mTc}} \mathrm{T}$ sestamibi and ${ }^{18} \mathrm{~F}$-FDG PET, unfortunately all lacking specificity. Peptide receptor scintigraphy and peptide receptor radionuclide therapy are successfully applied for imaging and therapy of somatostatin receptor-expressing neuroendocrine tumors using somatostatin receptor radioligands. On the basis of a similar rationale, radioligands targeting the gastrin-releasing peptide receptor (GRP-R) might offer a specific method for imaging and therapy of BC. The aim of this study was to explore the application of GRP-R radioligands for imaging and therapy of $B C$ by introducing valid preclinical in vitro and in vivo models. Methods: GRP-R expression of 50 clinical BC specimens and the correlation with ER expression was studied by in vitro autoradiography with the GRP-R agonist ${ }^{111} \mathrm{In}$-AMBA. GRP-R expression was also analyzed in $9 \mathrm{BC}$ cell lines applying ${ }^{111} \mathrm{In}-\mathrm{AMBA}$ internalization assays and quantitative reverse transcriptase polymerase chain reaction. In vitro cytotoxicity of ${ }^{177} \mathrm{Lu}$-AMBA was determined on the GRP-Rexpressing BC cell line T47D. SPECT/CT imaging and biodistribution were studied in mice with subcutaneous and orthotopic ER-positive T47D and MCF7 xenografts after injection of the GRP-R antagonist ${ }^{111}$ In-JMV4168. Results: Most of the human BC specimens (96\%) and BC cell lines (6/9) were found to express GRP-R. GRP-R tumor expression was positively $\left(P=0.026, \chi^{2}(4)=12,911\right)$ correlated with $\mathrm{ER}$ expression in the human $B C$ specimens. Treatment of T47D cells with $10^{-7} \mathrm{M} / 50 \mathrm{MBq}$ of ${ }^{177} \mathrm{Lu}$-AMBA resulted in $80 \%$ reduction of cells in vitro. Furthermore, subcutaneous and orthotopic tumors from both $\mathrm{BC}$ cell lines were successfully visualized in vivo by SPECT/CT using ${ }^{111} \mathrm{In}-J M V 4168$; T47D tumors exhibited a higher uptake than MCF7 xenografts. Conclusion: Targeting GRP-R-expressing BC tumors using GRP-R radioligands is promising for nuclear imaging and therapy, especially in ER-positive BC patients.

Key Words: breast cancer; PRS/PRRT; GRP-R; AMBA; JMV4168

J Nucl Med 2015; 56:752-757

DOI: 10.2967/jnumed.114.153023

Received Dec. 15, 2014; revision accepted Mar. 4, 2015.

For correspondence or reprints contact: Simone U. Dalm, Rm. Na620, P.O. Box 2040, 3000 CA Rotterdam, The Netherlands.

E-mail: s.dalm@erasmusmc.nl

Published online Mar. 19, 2015.

COPYRIGHT (C) 2015 by the Society of Nuclear Medicine and Molecular Imaging, Inc.
B estrogen receptor (ER), progesterone receptor, and human epidermal growth factor receptor 2 (1). On the basis of molecular characteristics, BC can be divided in 4 subgroups: luminal A and B, human epidermal growth factor receptor 2-like, and triple-negative tumors (2). The treatment and prognosis of BC are highly dependent on this classification. Mammography is the standard imaging technique used during nationwide screening of BC. Additional MR imaging or ultrasound can be performed (3). However, all 3 methods have drawbacks. Mammography lacks sensitivity and specificity, leading to false-positive and false-negative results. Especially in women with dense breast tissue, mammograms are hard to interpret (4). MR imaging and ultrasound also lack specificity. In addition, MR imaging is labor-intensive and expensive, whereas ultrasound is operator-dependent (5).

In nuclear medicine, methods to detect $\mathrm{BC}$ lesions and monitor response to treatment include ${ }^{201} \mathrm{TI}$ scintigraphy, ${ }^{99 \mathrm{~m}} \mathrm{Tc}$-sestamibi or ${ }^{99 \mathrm{~m}}$ Tc-tetrofosmin scintigraphy, and ${ }^{18} \mathrm{~F}$-FDG PET (6). Unfortunately, these methods also lack specificity.

Peptide receptor scintigraphy applies specific in vivo targeting of tumor lesions overexpressing a receptor of interest. This method was first described by Krenning et al. (7), using a radioactive somatostatin receptor (SSTR) ligand to image neuroendocrine tumors (NETs) overexpressing the SSTR subtype 2. To date, imaging with SSTR radioligands is routinely applied to characterize and evaluate (tumor localization, staging, monitoring) NETs (8). Furthermore, SSTR radioligands labeled with therapeutic radionuclides are successfully used for treatment of NET patients, using so-called peptide receptor radionuclide therapy (PRRT) (9).

Following the same principle, the gastrin-releasing peptide receptor (GRP-R) can be targeted. GRP-Rs are expressed on most BC cases; autoradiography studies by Reubi et al. (10) showed that $65 \%$ of the breast tumors analyzed expressed the GRP-R. Moreover, also lymph node metastases from primary tumors expressing GRP-R were positive (10-12). GRP-R binds a family of peptides, including the gastrin-releasing peptide; its C-terminal fragment neuromedin $\mathrm{C}$, both endogenous in humans; and the amphibian tetradecapeptide bombesin.

The application of GRP-R radioligands, analogs of the above native peptides, might offer a sensitive and specific method for imaging of GRP-R overexpressing BC. In addition, PRRT with 
radiolabeled GRP-R ligands might be feasible. Recently, multiple GRP-R radioligands, receptor agonists and antagonists, have been described that can be labeled with positron and $\gamma$ emitters, for example, ${ }^{68} \mathrm{Ga}$ and ${ }^{111} \mathrm{In}$, for imaging and with $\beta$ and $\alpha$ emitters, for example, ${ }^{177} \mathrm{Lu}$ and ${ }^{213} \mathrm{Bi}$, for therapeutic purposes, as yet primarily aiming at application in prostate cancer (13). Preclinical studies evaluating the potential of targeting the GRP-R in BC using GRP-R radioligands are limited. The aim of this study was to further characterize the GRP-R as a potential target for the visualization of BC lesions and for PRRT. For this purpose, we analyzed GRP-R expression in human clinical BC specimens and correlated this with ER expression. In addition, we used selected GRP-R-/ERexpressing human-derived $\mathrm{BC}$ cells to perform in vitro cytotoxicity assays and to develop suitable xenograft-bearing animal models for preclinical imaging studies.

\section{MATERIALS AND METHODS}

\section{Radiolabeled GRP-R Ligands}

For in vitro studies, the GRP-R agonist AMBA (BioSynthema) was used (14). Because radiolabeled AMBA exhibits high uptake in the gastrointestinal tract that potentially interferes with orthotopic tumor visualization, the GRP-R antagonist JMV4168 (University of Montpellier) was used for in vivo studies $(14,15)$. The GRP-R ligands were radiolabeled with ${ }^{111} \mathrm{In}$ (Covidien) or ${ }^{177} \mathrm{Lu}$ (IDB), using quenchers (10 $\mathrm{mM}$ methionine, $3.5 \mathrm{mM}$ ascorbic acid, and $3.5 \mathrm{mM}$ gentisic acid) to prevent radiolysis (16). Radiolabeling was performed for $20 \mathrm{~min}$ at $80^{\circ} \mathrm{C}$ as previously described (17), with a specific activity of 100 $\mathrm{MBq} / \mathrm{nmol}$ (for in vitro studies, both ${ }^{111} \mathrm{In}$ and ${ }^{177} \mathrm{Lu}$ ) or $150 \mathrm{MBq} /$ $\mathrm{nmol}$ (in vivo studies). Radiometal incorporation and radiochemical purity, measured by instant thin-layer chromatography on silica gel and high-pressure liquid chromatography as previously described (16), were greater than $95 \%$ and greater than $90 \%$, respectively.

\section{In Vitro Autoradiography on Human BC Specimens}

In vitro autoradiography was performed on 50 human $\mathrm{BC}$ specimens with known ER protein status. Specimens were selected from the Erasmus MC fresh frozen tissue bank. The study (MEC02.953) was approved by the Erasmus MC Medical Ethical Committee and adhered to the Code of Conduct of the Federation of Medical Scientific Societies in The Netherlands.

Frozen sections $(10 \mu \mathrm{m})$ of the BC specimens were incubated with $10^{-9}$ $\mathrm{M} / 0.1 \mathrm{MBq}$ of ${ }^{111} \mathrm{In}$-AMBA, without or with $10^{-6} \mathrm{M}$ unlabeled $\mathrm{Tyr}^{4}-$ bombesin (Sigma-Aldrich), to determine nonspecific binding, for $1 \mathrm{~h}$ and exposed to super resolution phosphor screens (PerkinElmer) for at least $24 \mathrm{~h}$ and read using the Cyclone (PerkinElmer). Adjacent tissue sections were stained with hematoxylin and eosin to determine tumor content. Autoradiography results were scored visually by 3 independent observers. Among the positive tumors, a division was made between tumors that were $1 \%-25 \%$, $26 \%-50 \%, 51 \%-75 \%$, and $76 \%-100 \%$ positive.

\section{Cell Culture, Internalization Assay, and Quantitative Reverse Transcriptase Polymerase Chain Reaction (RT-qPCR)}

Nine human-derived BC cell lines, obtained from the Department of Medical Oncology, Erasmus MC, with different molecular properties (Supplemental Table 1; supplemental materials are available online at http://jnm.snmjournals.org) were screened for GRP-R expression using internalization assays and RT-qPCR. Cell lines, authenticated by short tandem repeat profiling using the Powerplex STR kit (Promega), were cultured as described by Riaz et al. (18).

In the internalization assay, cells were incubated for $1 \mathrm{~h}$ at $37^{\circ} \mathrm{C}$ with $10^{-9} \mathrm{M} / 0.1 \mathrm{MBq}$ of ${ }^{111} \mathrm{In}$-AMBA (without or with $10^{-6} \mathrm{M}$ unlabeled $\mathrm{Tyr}^{4}$-bombesin). In addition, assays were performed using $10^{-7} \mathrm{M} / 10 \mathrm{MBq}, 10^{-8} \mathrm{M} / 1 \mathrm{MBq}$, and $10^{-9} \mathrm{M} / 0.1 \mathrm{MBq}$ of ${ }^{111} \mathrm{In}$-AMBA with incubation times of 1,2 , and $4 \mathrm{~h}$ to select the optimal conditions for the in vitro cytotoxicity studies. The internalization assay protocol is described in the supplemental materials.

To measure GRP-R messenger RNA levels of the BC cell lines, RNA was isolated using RNA-Bee (Campro Scientific) according to the manufacturer's instructions. Subsequently, complementary DNA synthesis and RT-qPCR were performed and normalized using the $\delta$ $\mathrm{Cq}$ method on the average of 2 reference genes (HMBS and HPRT1) as previously described (19). The quantification of target genes was performed using the Taqman probe-based gene expression assay, GRP-R, Hs01055872_m (Applied BioSystems/Life Technologies), according to the manufacturer's instructions.

\section{In Vitro Cytotoxicity Studies}

Cells $\left(12.5 \times 10^{6} / 5 \mathrm{~mL}\right.$ in a T25 culture flask, seeded $1 \mathrm{~d}$ before the experiment) were treated with $10^{-7} \mathrm{M} / 50 \mathrm{MBq}, 5 \times 10^{-8} \mathrm{M} / 25 \mathrm{MBq}$, or $10^{-8} \mathrm{M} / 5 \mathrm{MBq}$ of ${ }^{177} \mathrm{Lu}$-AMBA in $5 \mathrm{~mL}$ of internalization medium for $4 \mathrm{~h}$. Untreated cells, ${ }^{177} \mathrm{Lu}$-diethylenetriaminepentaacetic acid (DTPA)treated, and unlabeled AMBA-treated cells served as controls. After incubation, cells were washed twice with phosphate-buffered saline (GIBCO/Life Technologies) and detached using $0.1 \mathrm{mM}$ ethylenediaminetetraacetic acid. Cells were resuspended in medium, counted, and seeded in 3 wells of 12 -well plates (12,500 cells/well/1 $\mathrm{mL})$. Seven days after treatment, cells were fixed using $1 \mathrm{~mL}$ of $10 \%$ trichloroacetic acid (Sigma-Aldrich), and a sulforhodamine B colometric assay was performed to determine cell density. Results are expressed as percentages relative to untreated controls. The sulforhodamine B colometric assay protocol is described in the supplemental materials.

\section{In Vivo Imaging, Biodistribution, and In Vitro Autoradiography of BC Xenografts}

All animal studies were in agreement with the Animal Welfare Committee requirements of Eramus MC and conducted in accordance with accepted guidelines. BALB/c $n u / n u$ female mice (6-8 wk) (Janvier), supplemented with $\beta$-estradiol (4 mg/L; Sigma-Aldrich) in drinking water, were subcutaneously (between the shoulders) and orthotopically (left fourth mammary fat pad) inoculated with $8 \times 10^{6}$ T47D cells or $7 \times 10^{6} \mathrm{MCF} 7$ cells $(n=6$ for each cell line).

A 40-min SPECT/CT scan was acquired at 2 time points after inoculation (time point 1 [t1], $40 \pm 3 \mathrm{~d}$, and time point 2 [t2], $103 \pm 3 \mathrm{~d}$ ), using the NanoSPECT/CT scanner (Bioscan) $4 \mathrm{~h}$ after intravenous injection of approximately $35 \mathrm{MBq} / 200 \mathrm{pmol}$ of ${ }^{111}$ In-JMV4168, coinjected with $300 \mu \mathrm{g}$ of phosphoramidon (Peptides International Inc.) to inhibit in vivo enzymatic degradation of the peptide. During the scan acquisition, the animals were anesthetized with isoflurane $/ \mathrm{O}_{2}$ and body temperature was maintained. Bladder uptake was masked after reconstruction of the images. After the second scan, animals were euthanized, and tumors and organs were collected, weighed, and counted in a $\gamma$ counter. Data obtained were expressed as percentage injected dose per gram of tissue (\%ID/g). In addition, in vitro autoradiography was performed on the excised tumors, using ${ }^{111} \mathrm{In}$ JMV4168 without or with $10^{-6} \mathrm{M}$ unlabeled $\mathrm{Tyr}^{4}$-bombesin, to demonstrate receptor specificity of the tracer. Scanning, reconstruction, and counting details are described in the supplemental materials. Supplemental Figure 1 depicts the time line of the in vivo experiments.

\section{Statistics}

Statistical analyses are described in the supplemental materials.

\section{RESULTS}

\section{GRP-R Expression in Clinical BC Specimens}

The autoradiography results of 50 human BC tissue specimens with known ER protein status were scored for GRP-R expression. Hematoxylin and eosin staining of adjacent tissue sections was used 


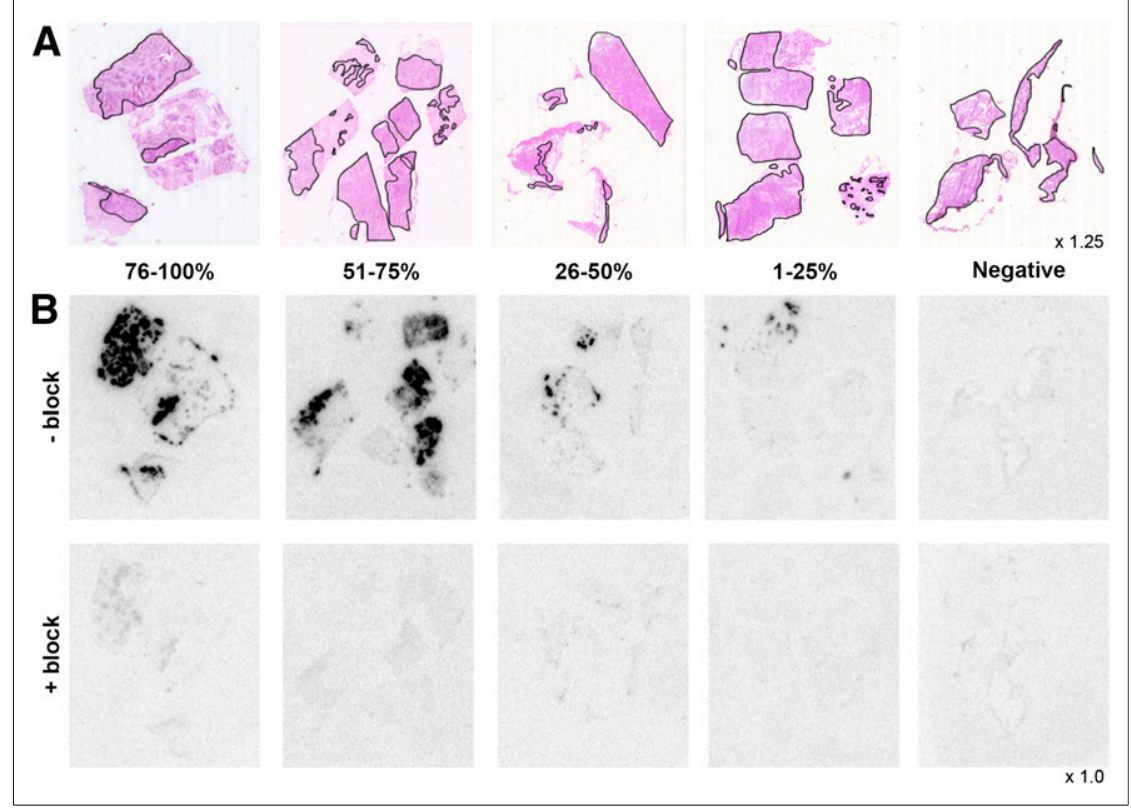

FIGURE 1. (A) Hematoxylin and eosin staining of sections indicating tumor-containing regions, corresponding to autoradiography results in $\mathrm{B}$. (B) Representative examples of ${ }^{111} \mathrm{In}$-AMBA binding to human BC specimens, without (-block) and with (+block) $10^{-6} \mathrm{M} \mathrm{Tyr}^{4}$-bombesin. Binding was GRP-R-specific because no binding was observed when the GRP-R was blocked by Tyr ${ }^{4}$ bombesin. Among GRP-R-positive tumors, a subdivision was made between tumors that were 1\%-25\%, 26\%-50\%, 51\%-75\%, and 76\%-100\% GRP-R-positive.

to discriminate between malignant and healthy tissue (Fig. 1A). Most (48/50 [96\%]) of the BC specimens analyzed were positive for GRP-R. The majority $(56 \%)$ of the samples showed greater than $75 \%$ positivity, indicating a homogeneous GRP-R expression. Of the remaining samples, $29 \%$ was $1 \%-25 \%$ positive, $8 \%$ was $26 \%-50 \%$ positive, and $6 \%$ was $51 \%-75 \%$ positive (Fig. 1B). In addition, a significant, positive $\left(P=0.026, \chi^{2}(4)=12,911\right)$ correlation was found between ER status and extent of GRP-R expression.

\section{GRP-R Expression in Human-Derived BC Cell Lines and In Vitro Cytotoxicity Studies}

Most of the BC cell lines examined (6/9) selectively bound and internalized ${ }^{111}$ In-AMBA, although to a variable extent (Fig. 2A). This process was GRP-R-specific, because binding and internalization were significantly decreased when an excess of unlabeled GRP-R ligand was added. The extent of ${ }^{111} \mathrm{In}$-AMBA binding and internalization seemed higher in ER-positive BC cell lines than in the ER-negative BC cell lines. However, the observed difference was not statistically significant $(P=0.757)$, probably because of the lower power of the cell line study than the clinical BC specimen study. Also, no clear correlation with progesterone receptor $(P=0.209)$ and human epidermal growth factor receptor 2 status $(P=0.192)$ of the BC cell lines was found.

To confirm that internalization levels correlated with GRP-R expression and were not attributed to, for example, receptor recycling efficiency, GRP-R expression was independently quantified by RT-qPCR (Supplemental Table 1). A significant positive correlation $\left(P=0.0108, \mathrm{R}_{\mathrm{s}}=0.8167\right)$ was found between messenger RNA levels of GRP-R and ${ }^{111}$ In-AMBA uptake (Fig. 2B).

The ER-positive cell lines T47D and MCF7 showed the highest uptake of ${ }^{111}$ In-AMBA. T47D was therefore selected for in vitro cytotoxicity experiments, and both T47D and MCF7 were used for inoculation in mice to create relevant in vivo models.

To determine the optimal incubation time and radioligand concentration for in vitro cytotoxicity studies, taking into account potential GRP-R saturation, T47D cells were incubated with 3 different concentrations of ${ }^{111} \mathrm{In}-\mathrm{AMBA}\left(10^{-7} \mathrm{M} / 10 \mathrm{MBq}\right.$, $10^{-8} \mathrm{M} / 1 \mathrm{MBq}$, and $\left.10^{-9} \mathrm{M} / 0.1 \mathrm{MBq}\right)$ for 3 different incubation times $(1,2$, and $4 \mathrm{~h})$. The highest absolute amount of ${ }^{111}$ InAMBA (counts per minute) was observed after $4 \mathrm{~h}$ of incubation with $10^{-7} \mathrm{M}{ }^{111} \mathrm{In}$ AMBA, both in the membrane-bound and in the internalized fraction (Fig. 3A).

When T47D cells were treated for $4 \mathrm{~h}$ with ${ }^{177} \mathrm{Lu}$-AMBA, a significant reduction in cell number of $20 \%, 50 \%$, and $80 \%$ was observed after incubation with $10^{-8} \mathrm{M} / 5$ $\mathrm{MBq}, 5 \times 10^{-8} \mathrm{M} / 25 \mathrm{MBq}$, or $10^{-7}$ $\mathrm{M} / 50 \mathrm{MBq}$ of ${ }^{177} \mathrm{Lu}-\mathrm{AMBA}$, respectively (Fig. 3B). Treatment with the same amount of ${ }^{177} \mathrm{Lu}$-DTPA for $4 \mathrm{~h}$, which is not actively internalized, did not inhibit cell proliferation, similarly to incubation with unlabeled AMBA. Therefore, the therapeutic effect of ${ }^{177} \mathrm{Lu}-\mathrm{AMBA}$ can be associated to the combination of specific GRP-R-mediated uptake and retention of ${ }^{177} \mathrm{Lu}$ within the cells over time.

\section{In Vivo Visualization of GRP-R Expression in BC Xenografts}

We successfully obtained T47D and MCF7 xenografts in immune-deficient female mice orally supplemented with estrogen.

At 2 time points after tumor cell inoculation, T47D and MCF7 xenografts were visualized using in vivo SPECT/CT imaging after an injection of approximately $35 \mathrm{MBq} / 200 \mathrm{pmol}$ of ${ }^{111} \mathrm{In}-$ JMV4168 $+300 \mu \mathrm{g}$ of phosphoramidon. T47D xenografts had

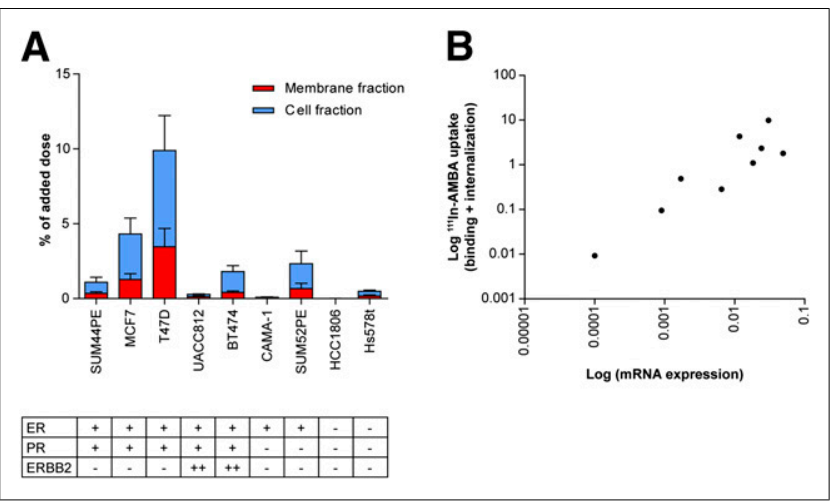

FIGURE 2. (A) Selective binding and internalization after $1 \mathrm{~h}$ of incubation with $10^{-9} \mathrm{M} / 0.1 \mathrm{MBq}$ of ${ }^{111} \mathrm{In}-\mathrm{AMBA}$, a GRP-R agonist. Nine humanderived $B C$ cell lines with different molecular properties (18) were screened. Both membrane- and internalized/cell fraction are displayed. Results shown are average of 3 independent experiments, each performed in triplicate (mean \pm SD). (B) Significant correlation $(P=0.0108$, $R_{s}=0.8167$ ) between GRP-R messenger RNA (mRNA) expression and level of ${ }^{111}$ In-AMBA uptake (membrane plus cell fraction). 


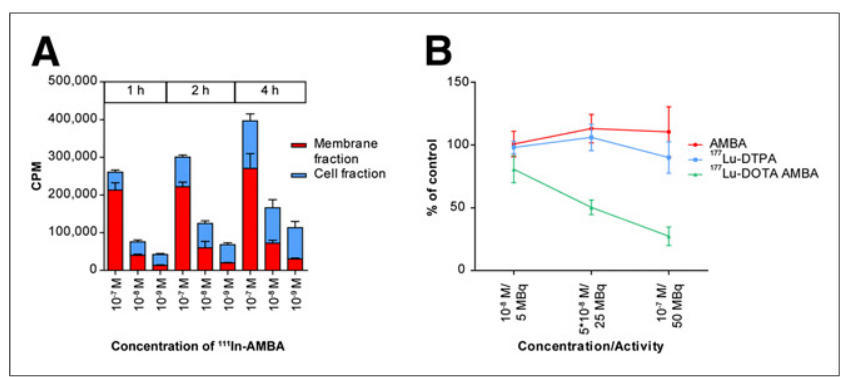

FIGURE 3. (A) Uptake of ${ }^{111}$ In-AMBA by GRP-R-expressing humanderived $B C$ cell line T47D, at 1,2 , and $4 \mathrm{~h}$ after incubation with $10^{-7} \mathrm{M} / 10$ $\mathrm{MBq}, 10^{-8} \mathrm{M} / 1 \mathrm{MBq}$, or $10^{-9} \mathrm{M} / 0.1 \mathrm{MBq}$ of ${ }^{111} \mathrm{In}$-AMBA. Results shown are average of 2 independent experiments, each performed in triplicate (mean \pm SD). (B) Treatment of T47D cells with 3 different concentrations of AMBA, ${ }^{177}$ Lu-DTPA, and ${ }^{177}$ Lu-AMBA for $4 \mathrm{~h}$. Significant reduction of $80 \%$ in cell viability was reached when cells were treated with $10^{-7} \mathrm{M} / 50 \mathrm{MBq}$ of ${ }^{177 \mathrm{Lu}-}$ AMBA, whereas no significant effects were observed when cells were similarly treated with AMBA or ${ }^{177}$ Lu-DTPA. Results shown are average of 3 independent experiments, each performed in triplicate (mean $\pm \mathrm{SD}$ ).

a significantly $(P<0.0001)$ higher uptake than MCF7 xenografts (748-1,706 vs. $169-658 \mathrm{kBq} / \mathrm{g}$ for subcutaneous tumors and $1,151-2,127$ vs. $189-672 \mathrm{kBq} / \mathrm{g}$ for orthotopic tumors). Therefore, T47D xenografts were visualized with higher contrast than MCF7 xenografts (Fig. 4). No significant difference in uptake between orthotopic and subcutaneous tumors of both T47D $(P=0.92)$ and MCF7 xenografts $(P=0.95)$ was determined. Biodistribution results obtained at $\mathrm{t} 2$ confirmed higher radiotracer uptake and a better tumor-to-kidney ratio (2.1 vs. 0.4$)$ in T47D than MCF7 xenografts (Fig. 5). In vitro autoradiography of the excised tumors demonstrated specific binding of ${ }^{111}$ In-JMV4168 (Supplemental Fig. 2). However, the proliferation of MCF7 xenografts was faster than that of T47D xenografts; orthotopic tumors ranged from 178 to $390 \mathrm{~mm}^{3}$ for T47D xenografts and from 755 to $1,830 \mathrm{~mm}^{3}$ for MCF7 xenografts at t1. At that time point, subcutaneous T47D xenografts ranged from 11 to $630 \mathrm{~mm}^{3}$, compared with 532-2,095 $\mathrm{mm}^{3}$ for MCF7 xenografts. As yet, we cannot exclude the effect of tumor size on radiotracer uptake. Two of 6 T47D subcutaneous tumors were small $\left(12.3\right.$ and $\left.4.0 \mathrm{~mm}^{3}\right)$ and were therefore excluded from the biodistribution study.

\section{DISCUSSION}

To gain more insight into the feasibility of diagnostic imaging and therapeutic applications of GRP-R radioligands in BC patients, we aimed to develop reliable preclinical models expressing the GRP-R based on well-characterized human-derived BC cell lines. We first confirmed GRP-R expression on clinical BC specimens and found that most $(96 \%)$ indeed expressed the GRP-R, which was higher than the $65 \%$ of GRP-R-expressing BC specimens reported by Reubi et al. (10). In the latter study, GRP-R, analyzed by in vitro autoradiography, was more frequently and more densely expressed than any other of the investigated targets, including neuropeptide $\mathrm{Y}$ receptor subtype 1, SSTR, and vasoactive intestinal peptide receptor. We observed a homogeneous GRP-R expression in more than half $(56 \%)$ of the tumors, supporting the conclusion that GRP-R is a suitable target for radioligands in BC patients.

Furthermore, a significant correlation was found between GRP-R and ER expression in the clinical BC specimens analyzed. ERpositive tumors were associated with higher GRP-R expression, indicating $\mathrm{BC}$ patients with ER-positive tumors as a potential target group for imaging or therapy with GRP-R radioligands. Our findings were in accordance with studies by Halmos et al. (12), showing a significant positive correlation between ER expression and GRP-R binding affinity examined on isolated cell membranes from $\mathrm{BC}$ samples. Because ER-positive tumors account for $75 \%$ of all breast tumors, GRP-R-based imaging could offer new imaging and therapeutic possibilities for most BC patients $(2,20)$. In addition, because current treatments with antihormonal agents, such as tamoxifen and aromatase inhibitors, are ineffective in about $40 \%$ of the ER-positive metastatic BC patients $(20,21)$, GRP-R ligands radiolabeled with particle emitters might offer new therapeutic options for these patients.

Furthermore, we found that most of the examined BC cell lines expressed the GRP-R. T47D was selected for in vitro therapy and, together with MCF7, for in vivo imaging studies.

Treatment of T47D cells with ${ }^{177} \mathrm{Lu}$-AMBA resulted in a significant decrease in cell viability, proving this cell line to be suitable as a model for future in vivo therapy studies in xenograft-bearing mice. An $80 \%$ decrease in cell viability was established using $10^{-7} \mathrm{M} / 50 \mathrm{MBq}$ of ${ }^{177} \mathrm{Lu}-\mathrm{AMBA}$. The uptake of ${ }^{177} \mathrm{Lu}$ by the tumor cells appeared to be a prerequisite, because the same amounts of ${ }^{177} \mathrm{Lu}$-DTPA, which does not bind or internalize, showed no significant effect on cell viability after 4-h exposure. Müller et al. (22) also studied the effect of

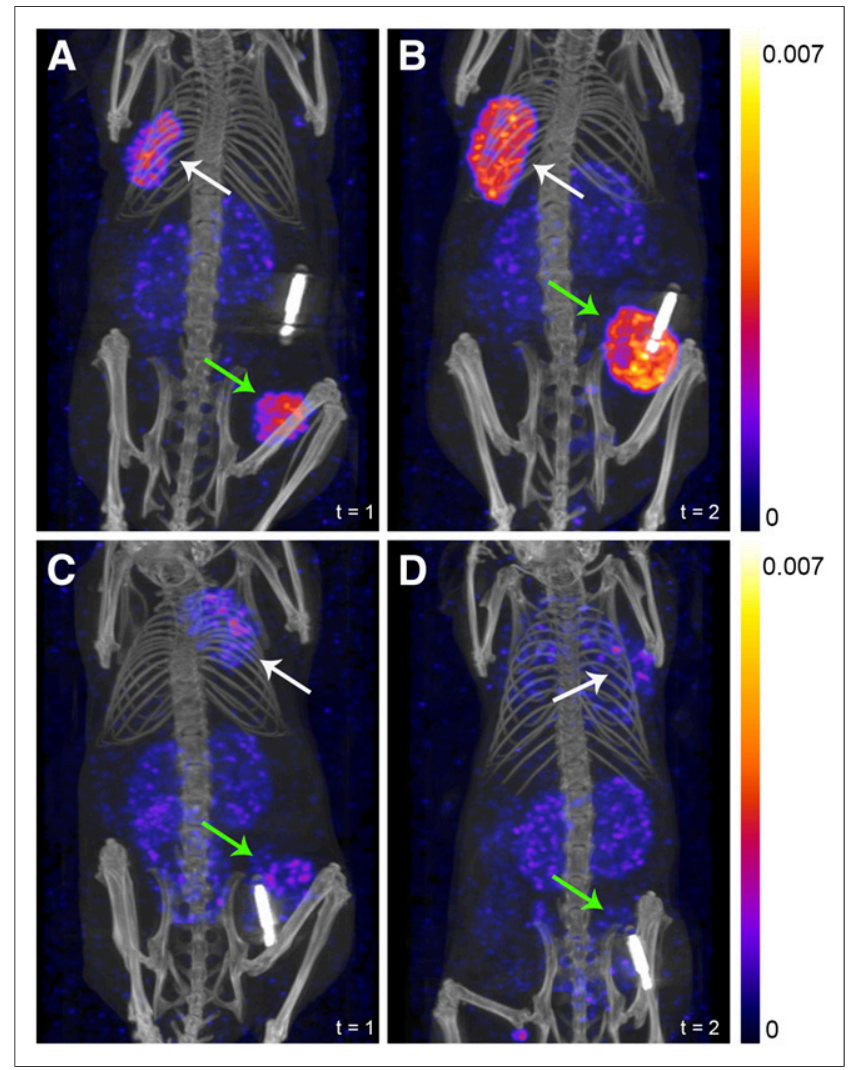

FIGURE 4. SPECT/CT scans indicating orthotopic (green arrows) and subcutaneous (white arrows) tumors of T47D and MCF7 xenograftbearing mice at $4 \mathrm{~h}$ after injection of approximately $35 \mathrm{MBq}(200 \mathrm{pmol})$ of ${ }^{111} \mathrm{In}-\mathrm{JMV} 4168+300 \mu \mathrm{g}$ of phosphoramidon. T47D xenografts were scanned at $\mathrm{t} 1=43 \mathrm{~d}(\mathrm{~A})$ and $\mathrm{t} 2=100 \mathrm{~d}(\mathrm{~B})$. MCF7 xenografts were scanned at $\mathrm{t} 1=37 \mathrm{~d}(\mathrm{C})$ and $\mathrm{t} 2=106 \mathrm{~d}(\mathrm{D})$. Bladder uptake is masked. Mice were provided with a chip for identification purposes. T47D xenografts were visualized with higher contrast than MCF7 xenografts. 


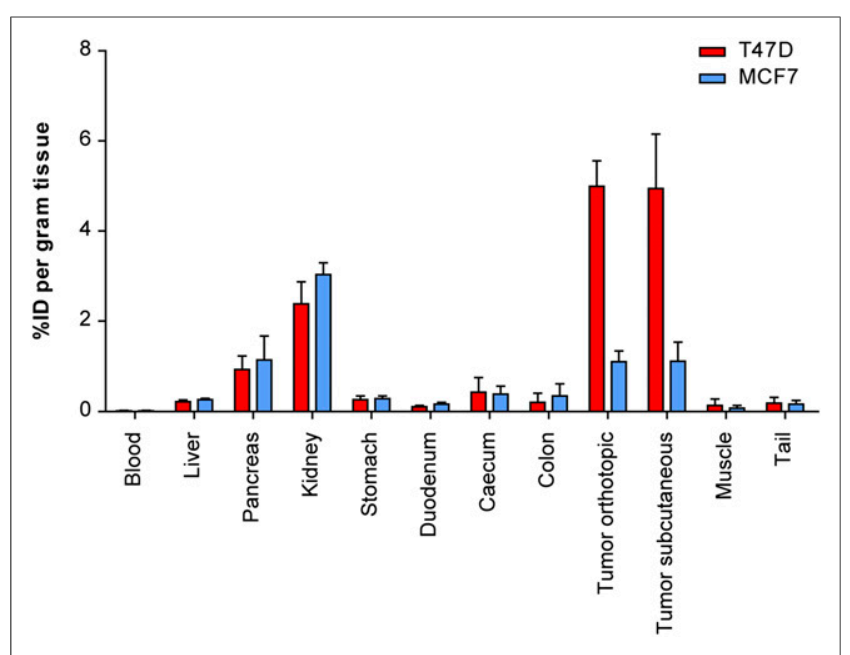

FIGURE 5. Quantification of ${ }^{111} \mathrm{In}-\mathrm{JMV} 4168$ uptake in tumors and organs collected after last scan (t2); $n=6$ for each mouse model (2 small subcutaneous T47D xenografts were excluded). Significantly $(P<$ 0.0001 ) higher uptake of ${ }^{111} \mathrm{In}-\mathrm{JMV} 4168$ was determined in T47D than in MCF7 xenografts.

${ }^{177} \mathrm{Lu}-\mathrm{DTPA}$ on cell viability, next to ${ }^{177} \mathrm{LuCl}_{3}$. In line with our results, treatment with ${ }^{177} \mathrm{LuCl}_{3}$, which is also internalized by cells, resulted in a larger decrease in cell viability than treatment with ${ }^{177} \mathrm{Lu}$-DTPA. In the study by Müller et al. (22), a decrease in cell viability was measured after treatment with ${ }^{177} \mathrm{Lu}$-DTPA as well, but cells were treated for $4 \mathrm{~d}$ with ${ }^{177} \mathrm{Lu}$-DTPA in contrast to the 4-h treatment in our study, which can explain the discrepancy.

On the basis of our in vitro cytotoxicity studies with ${ }^{177} \mathrm{Lu}-$ AMBA, we expect a similar effect of GRP-R antagonists on cell viability, because binding of the radioligand to the receptor results in cell membrane-bound accumulation of ${ }^{177} \mathrm{Lu}$, enabling radiationinduced DNA damage and thus cytotoxicity, despite the lack of internalization. A recent study by Wild et al. (23) comparing the application of ${ }^{177} \mathrm{Lu}$-labeled SSTR agonist and antagonist for PRRT in NET patients showed a higher tumor dose for the SSTR antagonist than for the agonist and therefore successful therapeutic effects, providing evidence that treatment with receptor antagonists is feasible.

According to previous studies, adverse effects have been reported during the clinical evaluation of ${ }^{177} \mathrm{Lu}$-AMBA in prostate cancer patients (24). Such undesirable effects can be evaded with GRP-R antagonists instead of agonists (25). For this reason and to prevent interference with orthotopic tumor visualization, the GRP-R antagonist JMV4168 was used for in vivo imaging studies.

With the aim of inhibiting the in vivo enzymatic degradation of ${ }^{111}$ In-JMV4168, which may potentially interfere with GRP-R targeting and tumor uptake, ${ }^{111}$ In-JMV4168 was coinjected with the neutral endopeptidase inhibitor phosphoramidon (26). Recent studies by Nock et al. (27) have shown significantly prolonged survival of several radioligands in the circulation when phosphoramidon was administered simultaneously. In the current study, ${ }^{111}$ InJMV4168 + phosphoramidon was successfully applied to visualize both orthotopic and subcutaneous BC tumors in mice, approximately $100 \mathrm{~mm}^{3}$ in size, indicating that GRP-R expression was sufficiently high to discriminate tumor lesions. Already approximately $1 \% \mathrm{ID} / \mathrm{g}$ uptake of MCF7 xenografts resulting in approximately $200 \mathrm{kBq}$ of ${ }^{111} \mathrm{In} / \mathrm{g}$ enabled visualization of tumor lesions, which was even higher for T47D xenografts, showing about 5
$\%$ ID/g uptake. Parry et al. (28) reported a similar tumor uptake in subcutaneous T47D xenografts using different GRP-R radioligands. Thus, these mouse models will now be used for future studies to examine the therapeutic potential of ${ }^{177} \mathrm{Lu}$-labeled GRP-R radioligands.

Recently several imaging studies using ${ }^{99 \mathrm{~m}} \mathrm{Tc}$-labeled bombesin analogs in BC patients were performed with promising results (29-32), identifying tumor lesions in patients suspected for BC based on mammography. In the most recent study by Shariati et al. (32), a sensitivity of $61 \%$ and specificity of $100 \%$ were reported, indicating that imaging with bombesin analogs is promising and deserves further investigation. Interestingly, 2 of these imaging studies described the identification of lymph node metastases, demonstrating the presence of the GRP-R on lymph node metastases next to primary tumor tissue $(31,32)$. However, the capacity to visualize distant metastases still needs to be established. In a study by Bergsma et al. (33), 50\% of the disseminated BC lesions studied were successfully visualized using the ${ }^{68} \mathrm{Ga}$-labeled GRP-R antagonist sarabesin-3 without adverse effects, once more showing the successful application of radiolabeled GRP-R antagonists in BC patients. None of these studies reported on correlation of positive scintigraphy with BC subtype and molecular markers.

Up to now, GRP-R-based PRRT has been performed targeting prostate cancer, either in xenograft-bearing animals, with GRP-R agonists or antagonists $(14,34)$, or in patients during a pilot study using ${ }^{177} \mathrm{Lu}$-AMBA (24). However, GRP-R-based PRRT is not yet being applied in BC animal models or patients. When GRP-R radioligands will be used for therapeutic purposes, the physiologic uptake in the pancreas should be considered regarding safety. Yet, the radiosensitivity of the pancreas is relatively low, and the fast pancreatic washout of radiolabeled GRP-R antagonists is favorable in this respect (35).

The results obtained in the current study together with the positive first experience with ${ }^{99 \mathrm{~m}} \mathrm{Tc}$ and ${ }^{68} \mathrm{Ga}$ GRP-R radioligands to localize $\mathrm{BC}$ are encouraging for future application of the socalled theranostic approach in BC, using, for example DOTA-coupled receptor ligands radiolabeled with ${ }^{111} \mathrm{In}$ and ${ }^{68} \mathrm{Ga}$ for imaging or with ${ }^{177} \mathrm{Lu},{ }^{90} \mathrm{Y}$, or ${ }^{213} \mathrm{Bi}$ for therapeutic purposes.

\section{CONCLUSION}

We confirmed GRP-R expression in clinical BC specimens, correlating with ER expression. Hence, ER-positive BC patients are potential candidates for imaging and PRRT using GRP-R radioligands. In addition, we successfully developed BC xenograft mouse models by inoculation of the selected ER- and GRP-R-positive BC cell lines T47D and MCF7 and visualized the generated tumors using ${ }^{111}$ In-JMV4168, coinjected with phosphoramidon. These mouse models will be used to study the therapeutic effects of ${ }^{177} \mathrm{Lu}$-labeled GRP-R radioligands, such as ${ }^{177} \mathrm{Lu}-J M V 4168$.

\section{DISCLOSURE}

The costs of publication of this article were defrayed in part by the payment of page charges. Therefore, and solely to indicate this fact, this article is hereby marked "advertisement" in accordance with 18 USC section 1734. This study was funded by the Erasmus MC grant "The Application of Radiolabeled Peptides in Breast Cancer." The study was also supported by the Cancer Genomics Netherlands, funded by the Netherlands Organisation for Scientific Research. No other potential conflict of interest relevant to this article was reported. 


\section{REFERENCES}

1. Perou CM, Sorlie T, Eisen MB, et al. Molecular portraits of human breast tumours. Nature. 2000;406:747-752.

2. Yersal O, Barutca S. Biological subtypes of breast cancer: prognostic and therapeutic implications. World J Clin Oncol. 2014;5:412-424.

3. Garcia EM, Storm ES, Atkinson L, Kenny E, Mitchell LS. Current breast imaging modalities, advances, and impact on breast care. Obstet Gynecol Clin North Am. 2013;40:429-457.

4. Humphrey LL, Helfand M, Chan BK, Woolf SH. Breast cancer screening: a summary of the evidence for the U.S. Preventive Services Task Force. Ann Intern Med. 2002; 137:347-360.

5. Mahoney MC, Newell MS. Screening MR imaging versus screening ultrasound: pros and cons. Magn Reson Imaging Clin N Am. 2013;21:495-508.

6. Schillaci O, Buscombe JR. Breast scintigraphy today: indications and limitations. Eur J Nucl Med Mol Imaging. 2004;31(suppl 1):S35-S45.

7. Krenning EP, Bakker WH, Breeman WA, et al. Localisation of endocrine-related tumours with radioiodinated analogue of somatostatin. Lancet. 1989;1: 242-244.

8. Kim KW, Krajewski KM, Nishino M, et al. Update on the management of gastroenteropancreatic neuroendocrine tumors with emphasis on the role of imaging. AJR. 2013;201:811-824.

9. Bodei L, Pepe G, Paganelli G. Peptide receptor radionuclide therapy (PRRT) of neuroendocrine tumors with somatostatin analogues. Eur Rev Med Pharmacol Sci. 2010;14:347-351.

10. Reubi C, Gugger M, Waser B. Co-expressed peptide receptors in breast cancer as a molecular basis for in vivo multireceptor tumour targeting. Eur J Nucl Med Mol Imaging. 2002;29:855-862.

11. Gugger M, Reubi JC. Gastrin-releasing peptide receptors in non-neoplastic and neoplastic human breast. Am J Pathol. 1999;155:2067-2076.

12. Halmos G, Wittliff JL, Schally AV. Characterization of bombesin/gastrin-releasing peptide receptors in human breast cancer and their relationship to steroid receptor expression. Cancer Res. 1995;55:280-287.

13. Reubi JC, Maecke HR. Peptide-based probes for cancer imaging. J Nucl Med. 2008;49:1735-1738.

14. Lantry LE, Cappelletti E, Maddalena ME, et al. ${ }^{177} \mathrm{Lu}-\mathrm{AMBA}$ : synthesis and characterization of a selective ${ }^{177} \mathrm{Lu}$-labeled GRP-R agonist for systemic radiotherapy of prostate cancer. J Nucl Med. 2006;47:1144-1152.

15. Marsouvanidis PJ, Nock BA, Hajjaj B, et al. Gastrin releasing peptide receptordirected radioligands based on a bombesin antagonist: synthesis, ${ }^{111} \mathrm{In}$-labeling, and preclinical profile. J Med Chem. 2013;56:2374-2384.

16. de Blois E, Chan HS, Konijnenberg M, de Zanger R, Breeman WA. Effectiveness of quenchers to reduce radiolysis of ${ }^{111} \mathrm{In}$ - or ${ }^{177} \mathrm{Lu}$-labelled methionine-containing regulatory peptides: maintaining radiochemical purity as measured by HPLC. Curr Top Med Chem. 2012;12:2677-2685.

17. De Blois E, Schroeder RJ, De Ridder CA, Van Weerden WM, Breeman WP, De Jong M. Improving radiopeptide pharmacokinetics by adjusting experimental conditions for bombesin receptor-mediated imaging of prostate cancer. $Q \mathrm{~J} \mathrm{Nucl}$ Med Mol Imaging. June 19, 2013 [Epub ahead of print].
18. Riaz M, van Jaarsveld MT, Hollestelle A, et al. miRNA expression profiling of 51 human breast cancer cell lines reveals subtype and driver mutation-specific miRNAs. Breast Cancer Res. 2013;15:R33.

19. Sieuwerts AM, Meijer-van Gelder ME, Timmermans M, et al. How ADAM-9 and ADAM-11 differentially from estrogen receptor predict response to tamoxifen treatment in patients with recurrent breast cancer: a retrospective study. Clin Cancer Res. 2005;11:7311-7321.

20. Droog M, Beelen K, Linn S, Zwart W. Tamoxifen resistance: from bench to bedside. Eur J Pharmacol. 2013;717:47-57.

21. Williams C, Lin CY. Oestrogen receptors in breast cancer: basic mechanisms and clinical implications. Ecancermedicalscience. 2013;7:370.

22. Müller C, Reber J, Haller S, et al. Direct in vitro and in vivo comparison of ${ }^{161} \mathrm{~Tb}$ and ${ }^{177} \mathrm{Lu}$ using a tumour-targeting folate conjugate. Eur J Nucl Med Mol Imaging. 2014;41:476-485.

23. Wild D, Fani M, Fischer R, et al. Comparison of somatostatin receptor agonist and antagonist for peptide receptor radionuclide therapy: a pilot study. $\mathrm{J} \mathrm{Nucl}$ Med. 2014;55:1248-1252.

24. Bodei L, Ferrari M, Nunn AD, et al. ${ }^{177} \mathrm{Lu}-\mathrm{AMBA}$ bombesin analogue in hormone refractory prostate cancer patients: a phase I escalation study with single-cycle administrations [abstract]. Eur J Nucl Med Mol Imaging. 2007;34(suppl 2):S221.

25. Cescato R, Maina T, Nock B, et al. Bombesin receptor antagonists may be preferable to agonists for tumor targeting. J Nucl Med. 2008;49:318-326.

26. Suda H, Aoyagi T, Takeuchi T, Umezawa H. Letter: a thermolysin inhibitor produced by actinomycetes-phospholamidon. J Antibiot (Tokyo). 1973;26:621-623.

27. Nock BA, Maina T, Krenning EP, de Jong M. "To serve and protect": enzyme inhibitors as radiopeptide escorts promote tumor targeting. J Nucl Med. 2014;55:121-127.

28. Parry JJ, Andrews R, Rogers BE. MicroPET imaging of breast cancer using radiolabeled bombesin analogs targeting the gastrin-releasing peptide receptor. Breast Cancer Res Treat. 2007;101:175-183.

29. Scopinaro F, Di Santo GP, Tofani A, et al. Fast cancer uptake of $99 \mathrm{~m}$ Tc-labelled bombesin ( ${ }^{99 m} \mathrm{Tc}$ BN1). In Vivo. 2005;19:1071-1076.

30. Soluri A, Scopinaro F, De Vincentis G, et al. 99MTC [13LEU] bombesin and a new gamma camera, the imaging probe, are able to guide mammotome breast biopsy. Anticancer Res. 2003;23:2139-2142.

31. Van de Wiele C, Phonteyne P, Pauwels P, et al. Gastrin-releasing peptide receptor imaging in human breast carcinoma versus immunohistochemistry. J Nucl Med. 2008;49:260-264.

32. Shariati F, Aryana K, Fattahi A, et al. Diagnostic value of ${ }^{99 m}$ Tc-bombesin scintigraphy for differentiation of malignant from benign breast lesions. Nucl Med Commun. 2014;35:620-625.

33. Bergsma HKH, Meuller D, Maina T, et al. PET/CT imaging with a novel ${ }^{68} \mathrm{Ga}-$ labelled GRP-receptor antagonist, "Sarabesin 3": first clinical data in patients with prostate and breast cancer [abstract]. J Nucl Med. 2013;54(suppl 2):280.

34. Dumont RA, Tamma M, Braun F, et al. Targeted radiotherapy of prostate cancer with a gastrin-releasing peptide receptor antagonist is effective as monotherapy and in combination with rapamycin. $J$ Nucl Med. 2013;54:762-769.

35. Stewart FA, Akleyev AV, Hauer-Jensen M, et al. ICRP publication 118: ICRP statement on tissue reactions and early and late effects of radiation in normal tissues and organs - threshold doses for tissue reactions in a radiation protection context. Ann ICRP. 2012;41:1-322. 